TITLE:

\title{
Mass attack by the ambrosia beetle Platypus quercivorus occurs in single trees and in groups of trees
}

$\operatorname{AUTHOR}(\mathrm{S})$ :

Yamasaki, Michimasa; Ito, Yasuto; Ando, Makoto

\section{CITATION:}

Yamasaki, Michimasa ...[et al]. Mass attack by the ambrosia beetle Platypus quercivorus occurs in single trees and in groups of trees. Canadian Journal of Forest Research 2014, 44(3): 243-249

ISSUE DATE:

2014-03

URL:

http://hdl.handle.net/2433/182933

\section{RIGHT:}

(c) 2014 NRC Canada; This is not the published version. Please cite only the published version.; この論文は出版社版でありません。引用の際に は出版社版をご確認ご利用ください。 
3 Mass attack by the ambrosia beetle Platypus quercivorus occurs in single trees and in

4 groups of trees

5

6

$7 \quad$ Author names and affiliations

8

9 Michimasa Yamasaki ${ }^{a}$, Yasuto Ito ${ }^{b}$, Makoto Ando ${ }^{c}$

$10{ }^{a}$ Laboratory of Forest Biology, Division of Forest and Biomaterials Science, Graduate

11 School of Agriculture, Kyoto University, Kitashirakawa Oiwake-cho, Sakyo-ku,

12 Kyoto 606-8502, Japan

$13 \quad$ E-mail: risei@kais.kyoto-u.ac.jp

$14{ }^{\mathrm{b}}$ Hyogo Prefectural Technology Center for Agriculture, Forestry and Fisheries, Ikaba

15 430, Yamasaki-cho, Shisou-shi, Hyogo 671-2515, Japan

16 E-mail: Yasuto_Itou@pref.hyogo.lg.jp

$17{ }^{\mathrm{c}}$ Field Science Education and Research Center, Kyoto University, Kitashirakawa

18 Oiwake-cho, Sakyo-ku, Kyoto 606-8502, Japan

19 E-mail: ando@kais.kyoto-u.ac.jp

20

21 Corresponding author

22

Michimasa Yamasaki

24 Laboratory of Forest Biology, Division of Forest and Biomaterials Science, Graduate

25 School of Agriculture, Kyoto University, Kitashirakawa Oiwake-cho, Sakyo-ku, Kyoto

26 606-8502, Japan

27 Tel: +81-75-753-6479

28 Fax: $+81-75-753-6129$

29 E-mail: risei@kais.kyoto-u.ac.jp 


\section{Abstract}

Bark and ambrosia beetles sometimes kill trees by attacking them en masse;

36 however, their attack is not necessarily successful. Less than half of the fagaceous

37 trees attacked by the ambrosia beetle, Platypus quercivorus, die, and the factors

38 affecting this mortality are still unknown. To examine this issue, the survival of all

39 stems of fagaceous trees attacked by the ambrosia beetle was investigated in a

40 secondary forest from 2008 to 2010 . In an area of 93 ha, 2130 stems (1278 genets) of

41 fagaceous trees were attacked by $P$. quercivorus during the study period, and 813 of

42 these stems died. A generalized additive mixed model was constructed to predict the

43 probability of mortality of the attacked stems. A best-fit model showed that the

44 probability of mortality was higher in Quercus crispula than in Castanea crenata. A

45 positive correlation was determined between the density of the attacked trees and the

46 probability of mortality, suggesting that mass attack of $P$. quercivorus occurs not only

47 on individual trees, but also on groups of trees. Assuming that trees attacked earlier in

48 the season have a higher probability of mortality, the observed negative effects of

49 altitude suggest that $P$. quercivorus initially seeks hosts at lower elevations. 
Introduction

52

In general, the search pattern of animals consists of 2 parts. Firstly, when

54 animals search a wide area without any resource cues, they move in a relatively straight

55 path without turning (ranging). Secondly, after they detect resources, they scour a local area (local search), and then repeat their ranging and local search until they reach or gather the necessary resources (Jander 1975). This search pattern is also followed by ambrosia and bark beetles, with tree selection usually consisting of multiple phases - detection of host trees, evaluation of tree suitability, and acceptance of the host

60 (Schoonhoven et al. 2005). Visual, olfactory, mechanosensory, and gustatory cues are considered to be involved in each phase.

Cues that ambrosia and bark beetles use to locate host trees can be predicted

63 from differences in characteristics between attacked and intact trees. These

64 differences have been determined in Pinus trees attacked by Dendroctonus ponderosae

65 Hopkins (Coleoptera: Curculionidae) (Coops et al. 2006; Negrón et al. 2008; Negrón and Popp 2004; Olsen et al. 1996; White et al. 2007), and the information can be used to assess risk (Coops et al. 2009; Robertson et al. 2008; Wulder et al. 2006; Wulder et al. 2009). However, analysis of damaged and intact trees without considering the multiple phases of host selection by the beetle may lead to incorrect interpretation of the results, because the cues in each phase are different. For example, the chemical factors involved in each phase of host selection by the conifer bark beetle were presumed to be different (Zhang and Schlyter 2004). Even within the same phase, different mechanisms may occur. Two conflicting mechanisms for the first phase of host selection by Dendroctonus beetles have been proposed: (1) attraction to host volatiles 
75 (Pureswaran and Borden 2005; Pureswaran et al. 2004); and (2) random landing on trees (Moeck et al. 1981; Wood 1982). This contradiction was explained by the difference in timing of these two behaviors within the first phase (Saint-Germain et al. 78 2007).

In Japan, the ambrosia beetle, Platypus quercivorus (Murayama) (Coleoptera:

80 Platypodidae), causes Japanese oak wilt by transporting the pathogenic fungus

81 Raffaelea quercivora Kubono et Shin-Ito (Ito et al. 1998; Kinuura and Kobayashi 2006;

82 Kubono and Ito 2002; Saito et al. 2001). The disease has spread throughout Japan

83 since the 1980s (Kobayashi and Ueda 2005). From June to October, adult males of $P$.

84 quercivorus fly to their host trees and bore shallow holes in them. Adult females join

85 the males and, after mating, the males and females make galleries in the sapwood and

86 deposit eggs at the terminal parts of these galleries. Hatched larvae feed on fungi that

87 have been transported from old host trees by adult females. The larvae grow into the

88 5th larval stage by winter, and then enter hibernation. Pupation starts in spring, and

89 new adults emerge starting in June (Soné et al. 1998). Infection by $P$. quercivorus occurs in 3 successive phases_-initial attack (Fig.

91 1a-b), mass attack (Fig. 1b-c), and cessation of attack. During the initial attack phase,

92 some male beetles find a host tree, excavate a hole in the bark, and use an aggregation

93 pheromone to attract their conspecifics (Tokoro et al. 2007). During the mass attack

94 phase, aggregated beetles attack the host tree en masse, and cause death. It has been

95 suggested that the attractiveness of trees bored by male beetles decreases after mating of

96 the beetles, and this leads to the cessation of attack (Ueda and Kobayashi 2001). Some trees survive the initial attack without receiving a mass attack, while

98 other trees die because of the mass attack induced by the aggregation pheromone. In 
99 the case of Quercus crispula Blume, the mortality of attacked trees was about $40 \%$

100 (Kamata et al. 2002). It is interesting to speculate under which situations the attack

101 status of trees shifts from initial attack to mass attack. Factors that could affect the

102 attack sequence include tree species, tree size, local environment, and timing of the 103 attack.

104 It has been suggested that $P$. quercivorus can discriminate between tree species (Yamasaki and Futai 2012) with different susceptibilities (Kobayashi et al.

106 2004); therefore, a difference in the probability of initiation of a mass attack may be

107 observed among tree species. The preference of $P$. quercivorus for targeting trees with

108 wider trunks (Akaishi et al. 2006; Yamasaki and Sakimoto 2009) may be explained by

109 the requirement of the species for large volumes of sapwood to construct galleries (Hijii

110 et al. 1991). A similar preference might also be observed in the initiation of a mass

111 attack.

112 Platypus quercivorus shows positive phototaxis (Igeta et al. 2003), and

113 therefore the host selection behavior of the beetle may depend on forest light

114 environments, which change temporally and spatially. Moreover, trees at different

115 topographies are subjected to varying levels of drought stress (Eckhardt and Menard

116 2008; Guarín and Taylor 2005), and this might affect the probability of their death after

117 attack. The initiation of a mass attack might also be affected by the density of the

118 attacked trees (DEA). A high DEA could expose surrounding trees to high levels of

119 aggregation pheromone, and result in a high probability of a mass attack. In addition,

120 at sites where the attack by $P$. quercivorus begins early in the season, trees will be

121 exposed to the attack for a longer period, which might increase their mortality risk. 
In the present study, we investigated the factors affecting the initiation of a

123 mass attack by $P$. quercivorus. We analyzed the survival data of attacked fagaceous

124 trees collected from a 93-ha area, surveyed over 3 years. Among the proposed factors,

125 the timing of the attack was impossible to measure throughout the wide area.

126 Therefore, based on our results, we discuss the indirect effect of topography related to

127 the timing of the attack.

128

\section{Material and methods}

130

Study site and search for infected trees

132

The present study was conducted in a secondary forest near the Hacchodaira

134 bog, located in eastern Kyoto Prefecture, Japan ( $35^{\circ} 14^{\prime}$ N, $135^{\circ} 50^{\prime}$ E, Fig. 2a). The

135 altitude of the study area ranged from $800 \mathrm{~m}$ to $970 \mathrm{~m}$ above sea level. The forest is in

136 a cool-temperate forest zone, and is dominated by Q. crispula and Castanea crenata

137 Sieb. et Zucc., which are highly susceptible and weakly susceptible, respectively, to

138 Japanese oak wilt.

139 Damage caused by P. quercivorus in the study area was first observed in 2008.

140 The 93-ha area was thoroughly searched from April to June in 2009, 2010, and 2011, to

141 identify fagaceous trees that had been attacked by $P$. quercivorus in the previous year.

142 The search effort was approximately $0.5 \mathrm{ha} / \mathrm{h}$ per person. Attacks by $P$. quercivorus

143 were identified by the presence of holes bored by the beetle, and frass accumulation at

144 the base of the tree. We identified the tree species and measured the diameter of each

145 attacked tree at $130 \mathrm{~cm}$ above the ground (diameter at breast height $[\mathrm{DBH}]$ ). The 
146 survival of each attacked tree was determined and recorded, by checking the leaf flush

147 of the investigated year. For multi-stemmed trees, DBH and survival were recorded

148 for each individual stem. Differences in the mortality rate among trees species were

149 tested using a 2-sample test for equality of proportions. system (GPS; GPS map 60 CSx, Garmin International, Inc., Olathe, Kansas). The longitude and latitude of each tree were projected onto a Transverse Mercator coordinate system in meter units. The altitude, topographic wetness index, and slope aspect of each location were calculated from a digital elevation model provided by the

155 Geospatial Information Authority of Japan. The topography projection and calculation were performed using GRASS geographic information system (GIS) software (GRASS Development Team 2010).

Preparation of explanatory variables

Although it was presumed that the DEA affected the probability of mortality of an individual tree, the scale of this was unclear. Therefore, we prepared the basal area of attacked fagaceous trees (BA) by generating buffers around each stem, using 10

164 different scales ranging from a $2.5-\mathrm{m}$ to a $25-\mathrm{m}$ radius at $2.5-\mathrm{m}$ intervals, and summing

165 the BA of stems included in each buffer. When the generated buffer crossed the

166 boundary of the study area, the BA was corrected by dividing the cumulative basal area,

167 by the proportion of the buffer area inside the study area to the total buffer area.

169 Fig. 1c) in the study area, and calculated the surrounding BA of each attacked tree as a 
170 candidate explanatory variable for predicting its mortality. The locations of intact

171 fagaceous trees (trees drawn with dotted lines in Fig. 1c) were not mapped; therefore,

172 the density of fagaceous trees, including intact and attacked trees (density of probable

173 host trees [DEP]), could not be calculated. As a substitute for DEP, we prepared the

174 categorical variable of vegetation type at the location of each attacked tree. Vegetation

175 type was determined using the vegetation map created by the national survey on the

176 natural environment, conducted by the Biodiversity Center of Japan, Ministry of the

177 Environment. Five types of vegetation were observed in the study area- (1)

178 secondary forest dominated by C. crenata and Q. crispula, (2) secondary forest

179 dominated by Japanese cedar (Cryptomeria japonica) and Q. crispula, (3) secondary

180 forest dominated by F. crenata and Q. crispula, (4) bog, and (5) grassland. Fagaceous

181 trees were not observed in the grasslands.

182 The candidate explanatory variables for predicting the probability of mortality

183 of trees attacked in the present year did not include the distance from trees attacked in

184 the previous year, because of the lack of information regarding attacked trees outside

185 the study area, and the prevention control of beetle emergence conducted in the study

186 area. In the study area, diameter measurements of the trees have been recorded at

187 3-year intervals since 1980, in 13 fixed plots (boxes in Fig. 2b). No damage caused by

188 P. quercivorus was observed in these plots or their surroundings, until the 10th

189 measurements were conducted in 2007. In 2008, trees killed by P. quercivorus were

190 first observed in the surrounding plot; therefore, nearly all the damage in 2008 was

191 thought to be caused by beetles from outside the study area. It was difficult to check

192 the locations of trees outside the study area that had been attacked in the previous year,

193 i.e., 2007. In addition, irrespective of the present study, damage control trials were 
194 conducted in the study area by Kyoto City, a conservator of this area. From May to

195 July in 2009 and 2010, the basal parts of trunks of all dead trees attacked in the previous

196 year were covered by vinyl sheets, up to $3 \mathrm{~m}$ or $4 \mathrm{~m}$ above the ground, to prevent beetle

197 emergence and minimize damage to other trees. Therefore, it was difficult to evaluate

198 the potential of trees attacked in the previous year to be sources of infection.

Model construction and selection

We modeled the probability of mortality of trees attacked by P. quercivorus

by using a generalized additive mixed model (GAMM) with the package gamm4 in R

2.15.3 (R Core Team 2013). The response variable used in the model was the survival

of stems ( 0 for surviving stems and 1 for dead stems). The response variable follows a binomial distribution, and therefore we set the link function of the model as a logit link.

The candidate explanatory variables were tree species, DBH, BA within a 2.5-25-m radius, altitude, topographic wetness index, slope aspect, and vegetation type. We assumed a nonlinear effect of slope aspect, and used a cyclic cubic regression spline as a smoother, to ensure that the values of the smoother at each end of slope aspect $-0^{\circ}$ and $360^{\circ}$ — were the same.

213 observed a high frequency of multi-stemmed fagaceous trees in the study area; further,

214 stems of the same genet (individual tree) were basally connected with each other,

215 implying a dependent structure. Therefore, the genet of trees, nested within tree

216 species, was included in the model as a random intercept (Zuur et al. 2009). Model

217 selection was performed in 2 steps, to obtain the best-fit model for predicting the 
218 probability of mortality of trees attacked by P. quercivorus. In the first step, the best

219 scale to calculate the density of attacked trees as an explanatory variable in the model

220 for predicting the probability of mortality was evaluated. In the second step, the

221 best-fit model with the lowest Akaike's information criterion (AIC) was selected from various combinations of candidate explanatory variables.

In the first step, 10 models were constructed — including the BA values at 10

different scales and all other candidate explanatory variables — and the model with the

lowest AIC was selected as the full model. In the second step, the best-fit model was selected from the full model, by comparing the AIC of all candidate models with various combinations of explanatory variables. We used 7 candidate explanatory variables (tree species, DBH, BA, altitude, topographic wetness index, slope aspect, and vegetation type), and therefore the inclusion or exclusion of each variable resulted in 128 combinations. Among these 128 models, the model with the lowest AIC was selected as the best-fit model. The relative variable importance (RVI) of each candidate explanatory variable was calculated using the Akaike weights of the 128 models. Comparisons of AIC and calculation of RVI were performed using the

234 MuMIn package in R.

\section{Results}

In the study area, $P$. quercivorus attacks were observed on 3 fagaceous

241 parentheses are the number of genets), respectively (Table 1). In general, the mortality 
242 rate of the attacked stems was higher in Q. crispula than in C. crenata (Table 1), and

243 these differences were significant for all 3 years (2-sample test for equality of

244 proportions: Chi-squared $=4.368, P=0.037$ for 2008 ; Chi-squared $=24.328, P<0.001$

245 for 2009; Chi-squared $=25.4, P<0.001$ for 2010 ). The study forest was dominated by

246 Q. crispula and C. crenata; the density of $Q$. serrata was low. In comparison with $Q$.

247 crispula and C. crenata, Q. serrata showed a much lower number of attacked stems

248 (Table 1); therefore, data on $Q$. serrata were excluded from the statistical analyses. In

2492010,40 stems of $Q$. crispula with a previous infection history (20 stems attacked in

2502008 and 20 stems attacked in 2009) were reattacked by P. quercivorus. Data on these

25140 stems were also excluded from the statistical analyses, because trees with a previous

252 infection history are known to be resistant to P. quercivorus (Soné et al. 1998; Urano

253 2000). Thus, data on the remaining 2063 stems were used for the statistical analyses.

254 The annual distribution of attacked $Q$. crispula in the study area differed from

255 that of C. crenata (Fig. 3). Clumps of attacked Q. crispula were observed at the lower

256 edges of the ridge face on the bog (Fig. 3). Generally, the density of attacked $Q$.

257 crispula was low on the west side of the study area (Fig. 3), where the vegetation was

258 dominated by Japanese cedar and Q. crispula (Fig. 2b). Similar to this area, the center

259 area (bog) was distinguished by a low density of attacked Q. crispula (Fig. 3). In 2008,

260 attacked C. crenata trees were distributed only on the north side; however, after 2009,

261 their distribution range extended to the south (Fig. 3).

We compared the ability of 10 models to predict the probability of mortality

263 of the attacked trees, by using tree species, DBH, altitude, topographic wetness index,

264 slope aspect, vegetation type, and BAs calculated at 10 different scales as explanatory

265 variables (Fig. 4). The AIC of the model decreased with an increase in the radius of 
the area used to calculate the BA, reaching its lowest value at a $15-\mathrm{m}$ radius; thereafter,

267 the AIC increased (Fig. 4). Therefore, the BA within a 15-m radius was used as a

268 candidate explanatory variable for modeling the probability of mortality of the attacked

269 trees.

$\mathrm{DBH}$, topographic wetness index, slope aspect, and vegetation type were not selected as explanatory variables in the best-fit model to predict the probability of mortality of the attacked trees. When $C$. crenata was set as a baseline, the estimated coefficient for Q. crispula was positive (tree species in Table 2). The estimated coefficient for the BA was also positive, indicating that this variable had significant positive effects on the probability of mortality of the attacked trees (Table 2). A significant negative effect on the probability of mortality was detected for altitude (Table 2). Tree species, BA, and altitude were equally important predictors in the model $(\mathrm{RVI}=0.99$ or 1.00 , Table 2$)$. Among the variables not selected for the best-fit model, DBH showed the highest RVI (0.51), while vegetation type showed the lowest

280 RVI (0.16).

\section{Discussion}

In the present study, we showed that the mortality of trees attacked by $P$.

quercivorus was significantly higher in Q. crispula than in C. crenata (Table 1); further, tree species was included in a best-fit model to predict the probability of mortality 
target (Yamasaki and Futai 2012), resulting in a higher probability of death for this species.

We demonstrated a positive effect of DEA on the probability of mortality

293 (Table 2), suggesting that mortality is low when the tree is individually attacked (i.e.,

294 with a low density of surrounding attacked trees), and high when the tree is attacked together with surrounding individuals (i.e., with a high density of surrounding attacked trees). In other words, changes in infection phases, from initial attack to mass attack (and subsequent death of the attacked tree), tend to occur when groups of trees are attacked. Therefore, it is likely that mass attacks of $P$. quercivorus occur not only in individual trees, but also in groups of trees. The ambrosia and bark beetles are thought to attack trees en masse to break down the host tree's resistance; further, the male beetles use an aggregation pheromone to attract conspecifics to an individual tree (Wood 1982). When attacked trees are clumped together (Fig. 3), the effects of the aggregation pheromone might also work on a larger scale, and the beetle might be attracted primarily to a group of trees. The BAs calculated at a 15-m-radius scale, i.e., $706.5 \mathrm{~m}^{2}$ in area, were good predictors of the probability of mortality of the attacked trees (Fig. 4), and may show the effective scale of clumped attacked trees as attractants to the beetle. In the case of initial attack by P. quercivorus, the effective DEP scale was $900 \mathrm{~m}^{2}$ (Yamasaki and Sakimoto 2009), which is slightly higher than the scale suggested in the present study. Beetles might begin to search for a suitable host tree within a wide range, and after detecting clumped host trees, might narrow the target,

311 and precipitate a mass attack. 
314 negative effects were explained by the shorter growing season for the beetles, caused by

315 the cooler temperatures at higher altitude (Williams et al. 2008). A similar negative

316 effect of altitude was determined in the present study (Table 2); however, considering

317 the small range of altitude (800-970 m) in the study area, it is improbable that the

318 length of the beetle's growing season differs among trees at different altitude. The

319 decrease in the probability of mortality of the attacked trees with an increase in altitude

320 may have arisen because of the host-seeking process of P. quercivorus in forests. A

321 previous study showed that $P$. quercivorus moves upward along slopes (Esaki et al.

322 2004). Platypus quercivorus might initially seek hosts at lower elevations in a forest,

323 and trees at the lower elevations might have a higher probability of mortality because of

324 their longer exposure to the beetle.

As reviewed in Fettig et al. (2007), insect resistance mechanisms are damaged

326 in trees that are stressed by factors such as drought, and this causes high susceptibility

327 to attack by the bark beetle. Moreover, under severe drought conditions, susceptibility

328 to beetle attack is further increased by other stress factors (Eatough Jones et al. 2004).

329 In the present study, we determined no effect of wetness on the mortality of the attacked

330 trees (the topographic wetness index was not selected in the best-fit model, Table 2).

331 Vegetation type was also not selected in the best-fit model (Table 2). The model

332 confirmed the lack of a relationship between water availability and the mortality of the

333 attacked trees. The dataset for the present study included 4 vegetation types, namely,

334 bog and 3 types of secondary forest. Water availability was evidently higher for trees

335 growing in a bog than for trees growing with other vegetation types; however, the

336 mortality of the attacked trees did not differ among vegetation types. The mortality of

337 trees attacked by $P$. quercivorus is considered to be mainly affected by the occurrence 
338 of mass attacks, and the local environment of trees may have little effect once a mass 339 attack is initiated.

$340 \quad$ Platypus quercivorus shows positive phototaxis, and might concentrate in

341 stands with more light (Igeta et al. 2003). A study conducted at Hacchodaira - the

342 same site as that used in the present study — showed a negative effect of DEP at a large

343 scale on the probability of beetle attack (Yamasaki et al. in press), suggesting a beetle

344 preference for bright stands with low DEP. Assuming that phototaxy functions during

345 the host-seeking process, the heterogeneity of light environments in a forest interior

346 caused by differences in slope aspect might have some effects on beetle aggregation.

347 However, in the present study, the mortality of attacked trees was not affected by slope

348 aspect (Table 2). Therefore, positive phototaxis may function at an earlier time, such

349 as immediately after beetle emergence from holes, in order to orient them toward the

350 sky. Nevertheless, many uncertainties regarding the flight behavior and flight height

351 of $P$. quercivorus exist.

352 Assuming that the DEP was uniform within the area of the same vegetation

353 type, exclusion of vegetation type (which showed the lowest RVI; Table 2) from the

354 model indicated no difference in mortality among attacked trees with different DEP

355 values. However, even for the same vegetation types, DEP differed at a local scale.

356 Therefore, the possibility that DEP affects the mortality of attacked trees cannot be

357 excluded. The inclusion of DEP at various scales as a candidate explanatory variable

358 for the model may clarify this issue. Moreover, to elucidate a more precise host

359 selection process of $P$. quercivorus, the inclusion of variables not measured in the

360 present study (for example, the distance from trees attacked in the previous year) as

361 candidate explanatory variables is required. 


\section{Conclusion}

364

Previous studies on trees attacked by $P$. quercivorus have considered all

366 probable host trees in a certain area as subjects of analysis, and have shown the

367 preferences of the beetles during their attack process with regard to species (Yamasaki

368 and Futai 2012), size (Akaishi et al. 2006; Yamasaki and Sakimoto 2009), and infection

369 history (Yamasaki and Futai 2008). However, the attack process of the beetles is

370 thought to be divided into 2 phases - the initial attack and the mass attack (Fig. 1). In

371 the present study, by analyzing only attacked trees, we clarified the factors affecting the

372 initiation of mass attack. The exclusion of DBH and vegetation type from the best-fit

373 model for predicting the probability of mortality of the attacked trees suggests that $P$.

374 quercivorus selects clumped, wide trees not as a mass attack target, but as an initial

375 attack target. The inclusion of BA in the best-fit model showed that P. quercivorus

376 selects dense stands of attacked trees as mass attack targets. The results of a 3-year

377 survey of beetle infection over wide areas revealed the detailed host selection process of

378 the ambrosia beetle, $P$. quercivorus.

379 


\section{Acknowledgments}

381

382

We thank all members of the Laboratory of Forest Biology, Kyoto University,

383 for their assistance in the fieldwork, and their help and advice during the study. We

384 would like to thank the associate editor and the two referees for their helpful comments

385 on a previous draft of this manuscript. This study was supported by a Grant-in-Aid for

386 Scientific Research from the Japan Society for the Promotion of Science (No.

387 22580162). 


\section{References}

Akaishi, D., Kamata, N., and Nakamura, K. 2006. Initial stage of an infestation of Platypus quercivorus (Coleoptera: Platypodidae) in a secondary forest dominated by Quercus serrata and Quercus variabilis (in Japanese with English summary). J. Jpn. For. Soc. 88: 274-278.

Coops, N.C., Waring, R.H., Wulder, M.A., and White, J.C. 2009. Prediction and assessment of bark beetle-induced mortality of lodgepole pine using estimates of stand vigor derived from remotely sensed data. Remote Sens. Environ. 113: 1058-1066. doi:10.1016/j.rse.2009.01.013.

Coops, N.C., Wulder, M.A., and White, J.C. 2006. Integrating remotely sensed and ancillary data sources to characterize a mountain pine beetle infestation. Remote Sens. Environ. 105: 83-97. doi:10.1016/j.rse.2006.06.007.

Eatough Jones, M., Paine, T.D., Fenn, M.E., and Poth, M.A. 2004. Influence of ozone and nitrogen deposition on bark beetle activity under drought conditions. For. Ecol. Manage. 200: 67-76. doi:10.1016/j.foreco.2004.06.003.

Eckhardt, L.G., and Menard, R.D. 2008. Topographic features associated with loblolly pine decline in central Alabama. For. Ecol. Manage. 255: 1735-1739. doi:10.1016/j.foreco.2007.11.036.

Esaki, K., Kato, K., and Kamata, N. 2004. Stand-level distribution and movement of Platypus quercivorus adults and patterns of incidence of new infestation. Agric. For. Entomol. 6: 71-82. doi:10.1111/j.1461-9563.2004.00206.x.

Fettig, C.J., Klepzig, K.D., Billings, R.F., Munson, A.S., Nebeker, T.E., Negrón, J.F., and Nowak, J.T. 2007. The effectiveness of vegetation management practices for 
prevention and control of bark beetle infestations in coniferous forests of the western and southern United States. For. Ecol. Manage. 238: 24-53. doi:10.1016/j.foreco.2006.10.011.

GRASS Development Team. 2010. Geographic Resources Analysis Support System (GRASS) Software, Version 6.4.0. Open Source Geospatial Foundation.

Guarín, A., and Taylor, A.H. 2005. Drought triggered tree mortality in mixed conifer forests in Yosemite National Park, California, USA. For. Ecol. Manage. 218: 229-244. doi:10.1016/j.foreco.2005.07.014.

Hijii, N., Kajimura, H., Urano, T., Kinuura, H., and Itami, H. 1991. The mass mortality of oak trees induced by Platypus quercivorus (Murayama) and Platypus calamus Blandford (Coleoptera: Platypodidae): the density and spatial distribution of attack by the beetles. J. Jpn. For. Soc. 73: 471-476.

Igeta, Y., Esaki, K., Kato, K., and Kamata, N. 2003. Influence of light condition on the stand-level distribution and movement of the ambrosia beetle Platypus quercivorus (Coleoptera: Platypodidae). Appl. Entmol. Zool. 38: 167-175.

Ito, S., Kubono, T., Sahashi, N., and Yamada, T. 1998. Associated fungi with the mass mortality of oak trees (in Japanese with English summary). J. Jpn. For. Soc. 80: $170-175$.

Jander, R. 1975. Ecological aspects of spatial orientation. Annu. Rev. Ecol. Syst. 6: 171-188. doi:10.1146/annurev.es.06.110175.001131.

Kamata, N., Esaki, K., Kato, K., Igeta, Y., and Wada, N. 2002. Potential impact of global warming on deciduous oak dieback caused by ambrosia fungus Raffaelea sp. carried by ambrosia beetle Platypus quercivorus (Coleoptera: Platypodidae) in Japan. Bull. Entomol. Res. 92: 119-126. doi:10.1079/BER2002158. 
Kinuura, H., and Kobayashi, M. 2006. Death of Quercus crispula by inoculation with adult Platypus quercivorus (Coleoptera : Platypodidae). Appl. Entmol. Zool. 41: 123-128. doi:10.1303/aez.2006.123.

Kobayashi, M., Nozaki, A., and Kinuura, H. 2004. Influence of sap on reproduction of Platypus quercivorus (Murayama) (Coleoptera: Platypodidae) (in Japanese). Appl. For. Sci. 13: 155-159.

Kobayashi, M., and Ueda, A. 2005. Wilt disease of Fagaceae trees caused by Platypus quercivorus (Murayama) (Coleoptera: Platypodidae) and the associated fungus: Aim is to clarify the damage factor (in Japanese with English summary). J. Jpn. For. Soc. 87: 435-450.

Kubono, T., and Ito, S. 2002. Raffaelea quercivora sp. nov. associated with mass mortality of Japanese oak, and the ambrosia beetle (Platypus quercivorus). Mycoscience 43: 255-260. doi:10.1007/s102670200037.

Moeck, H.A., Wood, D.L., and Lindahl Jr, K.Q. 1981. Host selection behavior of bark beetles (Coleoptera: Scolytidae) attacking Pinus ponderosa, with special emphasis on the western pine beetle, Dendroctonus brevicomis. J. Chem. Ecol. 7: 49-83.

Negrón, J.F., Allen, K., Cook, B., and Withrow, J.R., Jr. 2008. Susceptibility of ponderosa pine, Pinus ponderosa (Dougl. ex Laws.), to mountain pine beetle, Dendroctonus ponderosae Hopkins, attack in uneven-aged stands in the Black Hills of South Dakota and Wyoming USA. For. Ecol. Manage. 254: 327-334. doi:10.1016/j.foreco.2007.08.018.

Negrón, J.F., McMillin, J.D., Anhold, J.A., and Coulson, D. 2009. Bark beetle-caused mortality in a drought-affected ponderosa pine landscape in Arizona, USA. For. Ecol. Manage. 257: 1353-1362. doi:10.1016/j.foreco.2008.12.002. 
Negrón, J.F., and Popp, J.B. 2004. Probability of ponderosa pine infestation by mountain pine beetle in the Colorado Front Range. For. Ecol. Manage. 191: 17-27. doi:10.1016/j.foreco.2003.10.026.

Olsen, W.K., Schmid, J.M., and Mata, S.A. 1996. Stand characteristics associated with mountain pine beetle infestations in ponderosa pine. Forest Sci. 42: 310-327.

Pureswaran, D.S., and Borden, J.H. 2005. Primary attraction and kairomonal host discrimination in three species of Dendroctonus (Coleoptera: Scolytidae). Agric. For. Entomol. 7: 219-230. doi:10.1111/j.1461-9555.2005.00264.x.

Pureswaran, D.S., Gries, R., and Borden, J.H. 2004. Antennal responses of four species of tree-killing bark beetles (Coleoptera : Scolytidae) to volatiles collected from beetles, and their host and nonhost conifers. Chemoecology 14: 59-66. doi:10.1007/s00049-003-0261-1.

R Core Team. 2013. R: A language and environment for statistical computing. $\mathrm{R}$ Foundation for Statistical Computing, Vienna, Austria.

Robertson, C., Wulder, M.A., Nelson, T.A., and White, J.C. 2008. Risk rating for mountain pine beetle infestation of lodgepole pine forests over large areas with ordinal regression modelling. For. Ecol. Manage. 256: 900-912. doi:10.1016/j.foreco.2008.05.054.

Saint-Germain, M., Buddle, C.M., and Drapeau, P. 2007. Primary attraction and random landing in host-selection by wood-feeding insects: a matter of scale? Agric. For. Entomol. 9: 227-235. doi:10.1111/j.1461-9563.2007.00337.x.

Saito, S., Nakamura, H., Miura, N., Mikawa, K., and Onose, K. 2001. Process of mass oak mortality and the relation to Platypus quercivorus and its specific fungus (in Japanese with English summary). J. Jpn. For. Soc. 83: 58-61. 
Schoonhoven, L.M., Van Loon, J.J.A., and Dicke, M. 2005. Insect-Plant Biology. Second ed. Oxford University Press, New York.

Soné, K., Mori, T., and Ide, M. 1998. Life history of the oak borer, Platypus quercivorus (Murayama) (Coleoptera: Platypodidae). Appl. Entmol. Zool. 33: 67-75.

Tarno, H., Qi, H.Y., Endoh, R., Kobayashi, M., Goto, H., and Futai, K. 2011. Types of frass produced by the ambrosia beetle Platypus quercivorus during gallery construction, and host suitability of five tree species for the beetle. J. For. Res. 16: 68-75. doi:10.1007/s10310-010-0211-z.

Tokoro, M., Kobayashi, M., Saito, S., Kinuura, H., Nakashima, T., Shoda-Kagaya, E., Kashiwagi, T., Tebayashi, S., Kim, C.S., and Mori, K. 2007. Novel aggregation pheromone, $(1 S, 4 R)$-p-menth-2-en-1-ol, of the ambrosia beetle, Platypus quercivorus (Coleoptera: Platypodidae). Bull. For. For. Prod. Res. Inst. 6: 49-57.

Ueda, A., and Kobayashi, M. 2001. Aggregation of Platypus quercivorus (Murayama) (Coleoptera: Platypodidae) on oak logs bored by males of the species. J. For. Res. 6: 173-179.

Urano, T. 2000. Relationships between mass mortality of two oak species (Quercus mongolica Turcz. var. grosseserrata Rehd. et Wils. and Q. serrata Thunb.) and infestation by and reproduction of Platypus quercivorus (Murayama) (Coleopetra: Platypodidae). J. For. Res. 5: 187-193.

White, J.C., Coops, N.C., Hilker, T., Wulder, M.A., and Carroll, A.L. 2007. Detecting mountain pine beetle red attack damage with EO-1 Hyperion moisture indices. Int. J. Remote Sens. 28: 2111-2121. doi:10.1080/01431160600944028.

Williams, K.K., McMillin, J.D., DeGomez, T.E., Clancy, K.M., and Miller, A. 2008. Influence of elevation on bark beetle (Coleoptera: Curculionidae, Scolytinae) 
community structure and flight periodicity in ponderosa pine forests of Arizona. Environ. Entomol. 37: 94-109. doi:10.1603/0046-225X(2008)37[94:IOEOBB]2.0.CO;2.

Wood, D.L. 1982. The role of pheromones, kairomones, and allomones in the host selection and colonization behavior of bark beetles. Annu. Rev. Entomol. 27: 411-446.

Wulder, M.A., White, J.C., Bentz, B., Alvarez, M.F., and Coops, N.C. 2006. Estimating the probability of mountain pine beetle red-attack damage. Remote Sens. Environ. 101: 150-166. doi:10.1016/j.rse.2005.12.010.

Wulder, M.A., White, J.C., Carroll, A.L., and Coops, N.C. 2009. Challenges for the operational detection of mountain pine beetle green attack with remote sensing. Forest. Chron. 85: 32-38.

Yamasaki, M., and Futai, K. 2008. Host selection by Platypus quercivorus (Murayama) (Coleoptera: Platypodidae) before and after flying to trees. Appl. Entmol. Zool. 43: 249-257. doi:10.1303/aez.2008.249.

Yamasaki, M., and Futai, K. 2012. Discrimination among host tree species by the ambrosia beetle Platypus quercivorus. J. For. Res. 17: 149-155. doi:10.1007/s10310-011-0280-7.

Yamasaki, M., Ito, Y., and Ando, M. in press. The effect of stem density on the probability of attack by the ambrosia beetle Platypus quercivorus varies with spatial scale. Agric. For. Entomol. doi:10.1111/afe.12033.

Yamasaki, M., and Sakimoto, M. 2009. Predicting oak tree mortality caused by the ambrosia beetle Platypus quercivorus in a cool-temperate forest. J. Appl. Entmol. 133: 673-681. doi:10.1111/j.1439-0418.2009.01435.x. 
Zhang, Q.-H., and Schlyter, F. 2004. Olfactory recognition and behavioural avoidance of angiosperm nonhost volatiles by conifer-inhabiting bark beetles. Agric. For. Entomol. 6: 1-19. doi:10.1111/j.1461-9555.2004.00202.x.

Zuur, A.F., Ieno, E.N., Walker, N.J., Saveliev, A.A., and Smith, G.M. 2009. GLM and GAM for presence-absence and proportional data. In Mixed Effects Models and Extensions in Ecology with R. Springer Science+Business Media, LLC, New York. pp. 245-259. 
Table 1 Mortality rate of stems attacked by Platypus quercivorus, and number of attacked stems (within parentheses), in a secondary forest near the Hacchodaira bog, located in eastern Kyoto Prefecture, Japan. Data are separately shown for 3 fagaceous species, in 2008, 2009, and 2010. In all 3 years, the mortality rate was significantly higher in $Q$. crispula than in C. crenata (2-sample test for equality of proportions: Chi-squared $=4.368, P=0.037$ for 2008; Chi-squared $=24.328, P<$ 0.001 for 2009; Chi-squared $=25.4, P<0.001$ for 2010).

\begin{tabular}{|c|c|c|c|}
\hline & 2008 & 2009 & 2010 \\
\hline Quercus crispula & $40.3 \% \quad(325)$ & $45.5 \% \quad(453)$ & $39.5 \% \quad(1124)$ \\
\hline Quercus serrata & $50.0 \%$ & $0 \% \quad(8)$ & $0 \% \quad(17)$ \\
\hline Castanea crenata & $23.1 \% \quad(39)$ & $14.3 \% \quad(70)$ & $13.0 \% \quad(92)$ \\
\hline
\end{tabular}


Table 2 Estimated coefficients, their standard errors, and $z$-statistics of variables selected for a best-fit model $(n=2063$, AIC $=2196.764)$ to predict the probability of mortality of fagaceous trees caused by the ambrosia beetle, Platypus quercivorus, in a secondary forest near the Hacchodaira bog, located in eastern Kyoto Prefecture, Japan.

\begin{tabular}{|c|c|c|c|c|c|}
\hline Variable & Estimate $^{\mathrm{a}}$ & $\mathrm{SE}$ & $z$ & $P^{\mathrm{b}}$ & $\mathrm{RVI}^{\mathrm{c}}$ \\
\hline Tree species $^{\mathrm{d}}$ & 3.85180 & 1.05806 & 3.640 & $0.00027 * * *$ & 1.00 \\
\hline $\mathrm{BA}^{\mathrm{e}}$ & 4.03259 & 0.73263 & 5.504 & $<0.00001 * * *$ & 1.00 \\
\hline Altitude & -0.02997 & 0.00904 & -3.316 & $0.00091 * * *$ & 0.99 \\
\hline $\mathrm{DBH}^{\mathrm{f}}$ & - & - & - & - & 0.51 \\
\hline $\begin{array}{l}\text { Topographic } \\
\text { wetness index }\end{array}$ & - & - & - & - & 0.39 \\
\hline Slope aspect & - & - & - & - & 0.39 \\
\hline Vegetation type & - & - & - & - & 0.16 \\
\hline
\end{tabular}

${ }^{a}$ Variables without estimates were not selected as explanatory variables for a best-fit model

${ }^{\mathrm{b}}$ Significant differences from zero were tested using $z$-statistics $(* * P<0.01, * * * P<$ $0.001)$

${ }^{\mathrm{c}} \mathrm{RVI}=$ relative variable importance, calculated using Akaike weights of all candidate models

${ }^{\mathrm{d}}$ Tree species $=$ species of attacked tree (estimated intercept for Quercus crispula, when Castanea crenata is set as a baseline, is shown)

${ }^{\mathrm{e}} \mathrm{BA}=$ basal area of attacked fagaceous trees within a $15-\mathrm{m}$ radius

${ }^{\mathrm{f}} \mathrm{DBH}=$ diameter at breast height, i.e., diameter of the attacked tree at $130 \mathrm{~cm}$ above ground 
Fig. 1 Course of infection by Platypus quercivorus. (a) Intact fagaceous trees distributed in a forest. (b) Some trees receive an initial attack by the beetle. (c) Mass attack occurs on some of the trees that received the initial attack. White, gray, and black trees show intact trees, trees that received an initial attack, and trees that received a mass attack subsequent to the initial attack, respectively. Trees drawn with a dotted line are not a target of the mass attack.

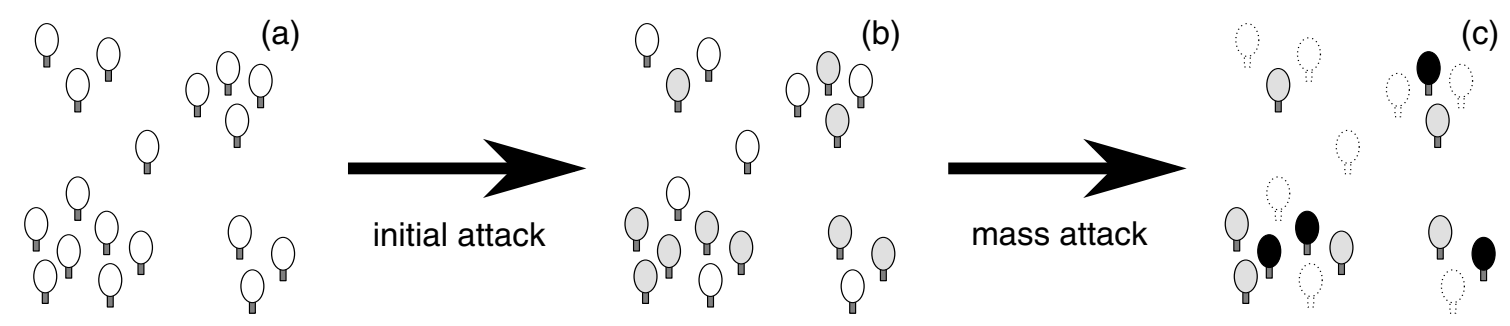


Fig. 2 (a) Location of the study site in Japan. (b) Vegetation type in and around the study area. The thick line shows the study area. The white, gray, dark gray, black, and light gray areas show the secondary forest dominated by Castanea crenata and Quercus crispula, other types of secondary forest, artificial forest, bogs, and other types of vegetation such as grasslands, respectively. Gray lines show contour lines at 10-m intervals. Boxes show the location of 13 fixed plots set up in 1980.
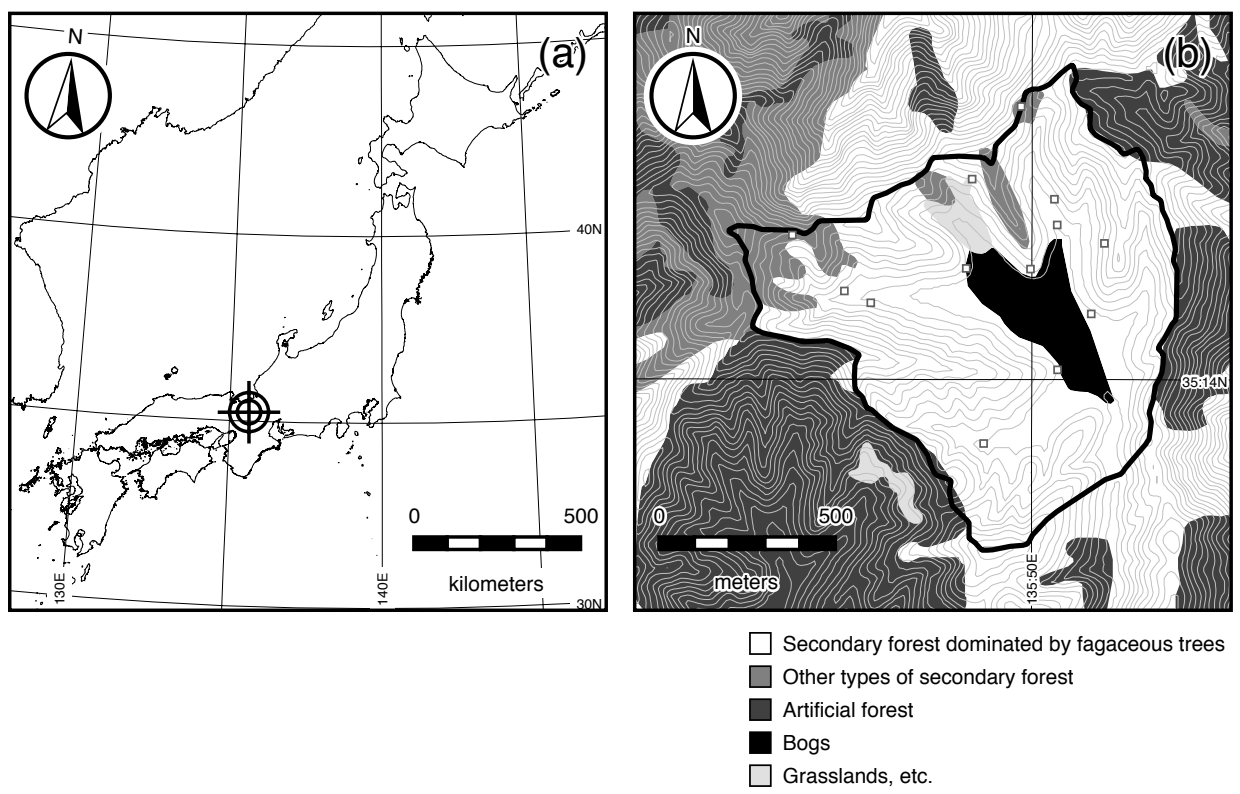
Fig. 3 Distribution of Quercus crispula (top) and Castanea crenata (bottom) attacked by Platypus quercivorus in 2008 (left), 2009 (center), and 2010 (right) in a secondary forest near the Hacchodaira bog, located in eastern Kyoto Prefecture, Japan. Circle, surviving tree; cross, dead tree.
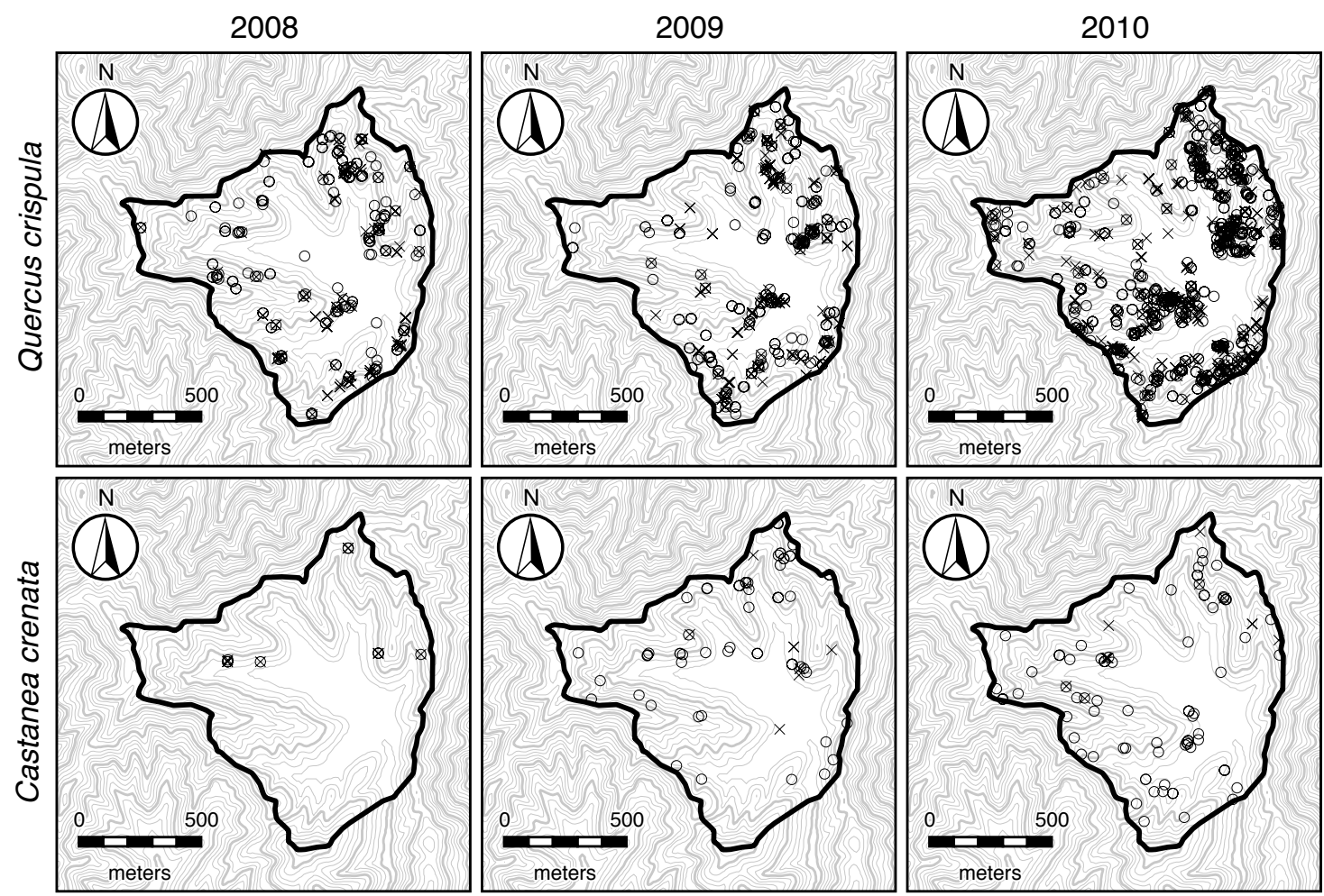
Fig. 4 Akaike's information criterion (AIC) of 10 different models to predict the mortality probability of fagaceous trees attacked by Platypus quercivorus in a secondary forest near the Hacchodaira bog, located in eastern Kyoto Prefecture, Japan. The basal areas of attacked trees calculated within a radius of $2.5-25 \mathrm{~m}$ of the target tree were included in each model, together with the other candidate explanatory variables.

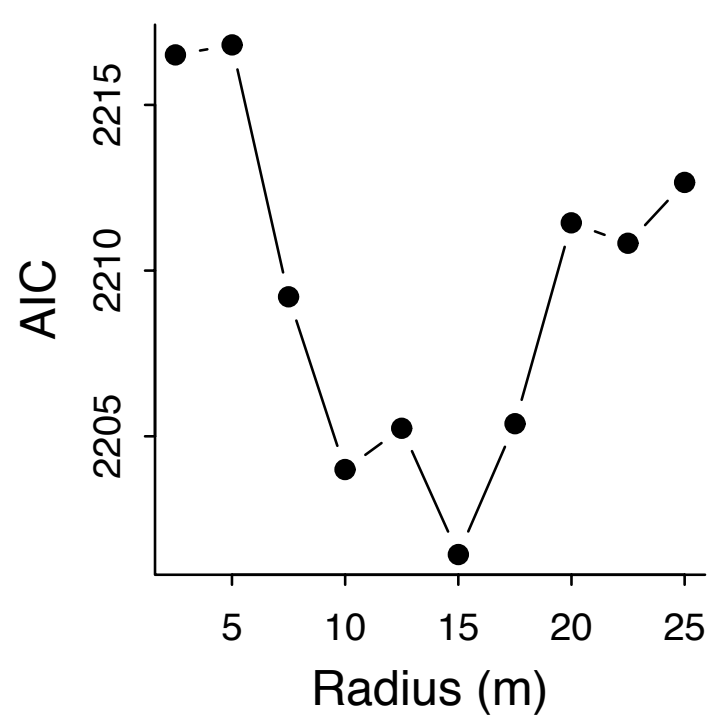

